\title{
ML212: A small-molecule probe for investigating fluconazole resistance mechanisms in Candida albicans
}

\author{
Willmen Youngsaye ${ }^{1}$, Cathy L. Hartland ${ }^{1}$, Barbara J. Morgan ${ }^{1}$, Amal Ting ${ }^{1}$, \\ Partha P. Nag ${ }^{1}$, Benjamin Vincent ${ }^{2,3}$, Carrie A. Mosher ${ }^{1}$, Joshua A. Bittker ${ }^{1}$, \\ Sivaraman Dandapani ${ }^{1}$, Michelle Palmer ${ }^{1}$, Luke Whitesell ${ }^{2}$, \\ Susan Lindquist ${ }^{2,4}$, Stuart L. Schreiber ${ }^{1,5}$ and Benito Munoz ${ }^{* 1}$
}

\section{Full Research Paper}

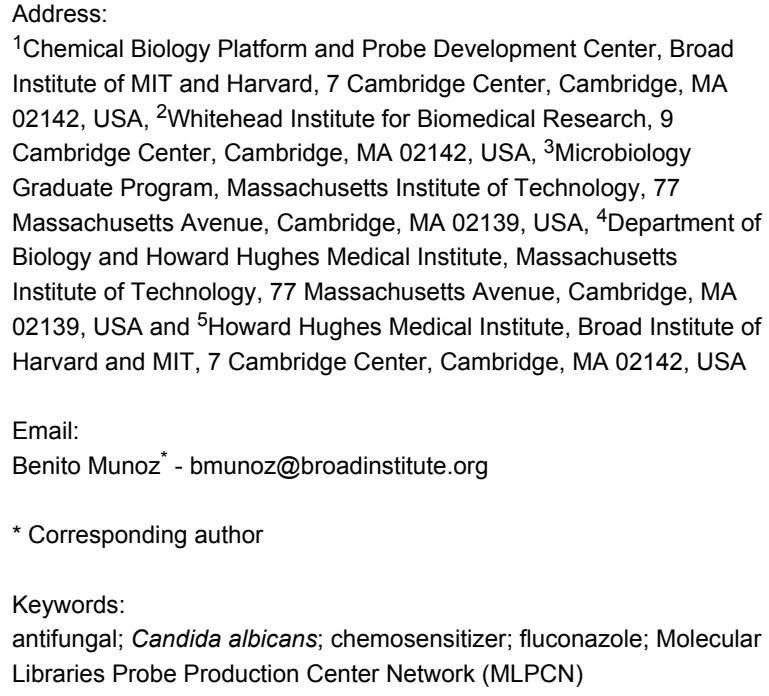

${ }^{1}$ Chemical Biology Platform and Probe Development Center, Broad Institute of MIT and Harvard, 7 Cambridge Center, Cambridge, MA 02142, USA, ${ }^{2}$ Whitehead Institute for Biomedical Research, 9 Cambridge Center, Cambridge, MA 02142, USA, ${ }^{3}$ Microbiology Graduate Program, Massachusetts Institute of Technology, 77 Massachusetts Avenue, Cambridge, MA 02139, USA, ${ }^{4}$ Department of Biology and Howard Hughes Medical Institute, Massachusetts Institute of Technology, 77 Massachusetts Avenue, Cambridge, MA 02139, USA and ${ }^{5}$ Howard Hughes Medical Institute, Broad Institute of Harvard and MIT, 7 Cambridge Center, Cambridge, MA 02142, USA

Email:

Benito Munoz* - bmunoz@broadinstitute.org

* Corresponding author

Keywords:

antifungal; Candida albicans; chemosensitizer; fluconazole; Molecular Libraries Probe Production Center Network (MLPCN)

\author{
Beilstein J. Org. Chem. 2013, 9, 1501-1507 \\ doi:10.3762/bjoc.9.171
}

Received: 12 March 2013

Accepted: 10 June 2013

Published: 26 July 2013

This article is part of the Thematic Series "Synthetic probes for the study of biological function".

Guest Editor: J. Aubé

(C) 2013 Youngsaye et al; licensee Beilstein-Institut.

License and terms: see end of document.

\begin{abstract}
The National Institutes of Health Molecular Libraries and Probe Production Centers Network (NIH-MLPCN) screened $>300,000$ compounds to evaluate their ability to restore fluconazole susceptibility in resistant Candida albicans isolates. Additional counter screens were incorporated to remove substances inherently toxic to either mammalian or fungal cells. A substituted indazole possessing the desired bioactivity profile was selected for further development, and initial investigation of structure-activity relationships led to the discovery of ML212.
\end{abstract}

\section{Introduction}

Discovery of antimicrobial agents possessing unique structural motifs or a novel mechanism of action is critical to counter and control the rising incidence of drug-resistant pathogens [1-6]
Chemosensitization of resistant organisms is a complementary approach that capitalizes upon the existing arsenal of antimicrobials to combat this medical dilemma [7-10]. By undermining 
the resistance mechanisms of the target pathogen, it is possible to restore efficacy to previously ineffective drugs thereby prolonging their status as frontline treatments. This, in turn, affords critical lead-time towards the development of novel antimicrobial drugs.

The National Institutes of Health Molecular Libraries and Probe Production Centers Network (NIH-MLPCN) recently performed a high-throughput screening (HTS) campaign to search for potential chemosensitizers of the pathogenic fungus Candida albicans [11]. The C. albicans clinical isolates used in this study demonstrate a range of resistance to the widely prescribed triazole antimycotic fluconazole (Flc) [12], and the objective was to identify novel small molecules capable of surmounting this inherent resistance [13-16]. The screen was conducted by using a cell-based assay with integrated counter screens to remove compounds acting through previously established methods for overturning drug resistance in C. albicans. In addition, substances intrinsically toxic to either mammalian or fungal cells were eliminated.

\section{Results and Discussion \\ Screening results}

In order to identify nonfungitoxic chemosensitizers of Candida albicans, compounds from the NIH's Molecular Libraries Small Molecule Repository (MLSMR) [17] were evaluated in the screening cascade summarized in Figure 1. The C. albicans strains used in the primary screen and secondary assay 1

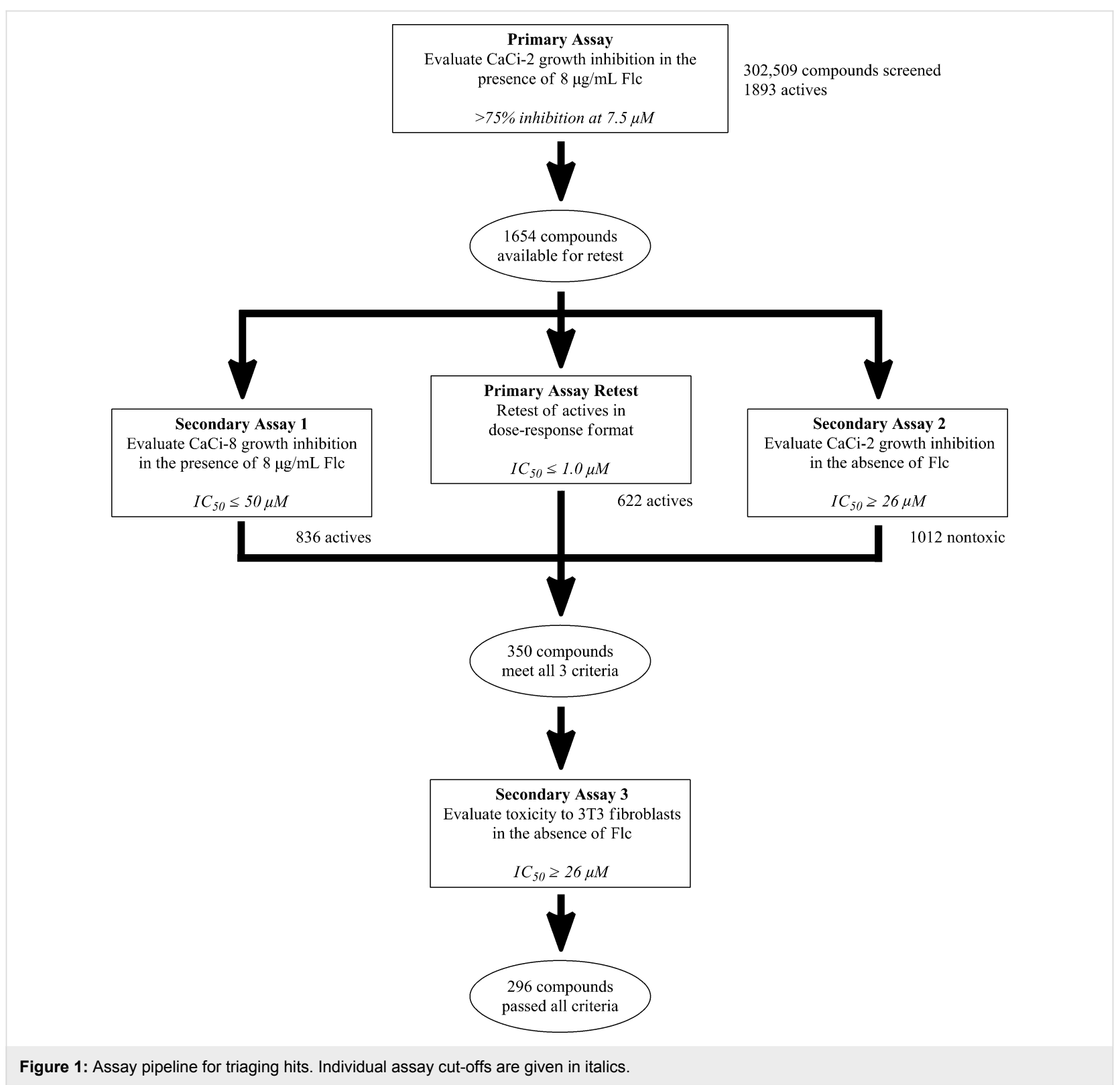


(CaCi-2 and CaCi-8, respectively) are both clinical isolates that partially respond to fluconazole treatment [12]. The minimum inhibitory concentration (MIC) of fluconazole against $\mathrm{CaCi}-2$ and $\mathrm{CaCi}-8$ was reported to be $2 \mu \mathrm{g} / \mathrm{mL}$ and $8 \mu \mathrm{g} / \mathrm{mL}$, respectively [12]. However in our hands, these strains continue to proliferate steadily (albeit at a reduced rate) when treated with fluconazole at or above the reported MIC. This behavior may contribute to the inability of fluconazole therapy to effectively clear the infection and allows for the further development of resistance [12].

A total of 302,509 compounds from the MLSMR were tested at $7.5 \mu \mathrm{M}$ for their ability to inhibit completely the growth of CaCi-2 cells that are concurrently treated with $8 \mu \mathrm{g} / \mathrm{mL}$ fluconazole (Figure 1). With a minimum requirement of $75 \%$ inhibition, 1893 actives were recorded, corresponding to an overall hit rate of $0.6 \%$. Of the active compounds, 1654 were available for retesting in a dose-response format. This subset was resubjected to the primary assay and was also tested concurrently in two secondary assays. Secondary assay 1 measured chemosensitization of the more resistant $\mathrm{CaCi}-8$ strain. Secondary assay 2 eliminated anything with inherently antifungal activity. These three assays cooperatively removed almost $80 \%$ of the original hits, leaving 350 candidates. A final assay (secondary assay 3 ) was incorporated to discard any compound displaying toxicity to mammalian fibroblasts. The fibroblast toxicity assay removed another 54 compounds to leave a total of 296 hits.

From the 296 hits remaining, 29 were selected for revalidation from dry powders obtained from commercial vendors or resynthesis. Once their identity and purity was ascertained by LCMS and ${ }^{1} \mathrm{H}$ NMR analysis, these 29 candidates were tested once more in the entire assay tree outlined previously in Figure 1. Following this re-evaluation, methyl 3-phenyl- $1 H$-indazole acetate (1, Figure 2) emerged as an attractive candidate for further development. A commercial sample of compound $\mathbf{1}$ shows good activity against $\mathrm{CaCi}-2$ and $\mathrm{CaCi}-8\left(\mathrm{IC}_{50}=0.8\right.$ and $2.3 \mu \mathrm{M}$, respectively) with no apparent effect on $3 \mathrm{~T} 3$ fibroblasts $\left(\mathrm{IC}_{50}>26 \mu \mathrm{M}\right)$. Compound 1 also possesses good solubility in PBS (79 $\mu \mathrm{M})$ and is synthetically tractable with several points of diversity readily accessible. Consequently, compound $\mathbf{1}$ and a collection of closely related analogues were prepared to enable investigation of possible structure-activity relationships (SAR) [18]. In addition to indazole 1, two other structurally distinct scaffolds (2 and 3) were also selected for follow-up studies and those works are communicated elsewhere $[19,20]$.

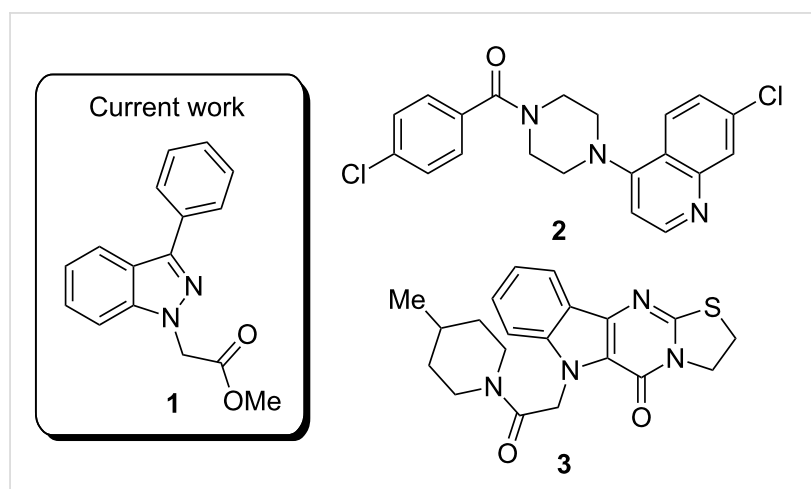

Figure 2: Hit compounds selected for further optimization

\section{Chemistry}

Two different routes were adopted to access the various functionalized indazoles required to evaluate the SAR associated with hit compound $\mathbf{1}$ (Scheme 1). The robust Suzuki-Miyaura

Synthesis of substituted 3-arylindazoles:

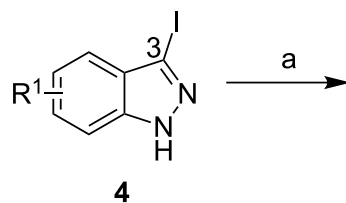

Synthesis of 3-alkylindazoles:<smiles>O=Cc1ccccc1F</smiles>

8<smiles>[R]C(C)(C)OC(=O)n1nc(I)c2c1C=C[R1]C=C2</smiles>

b<smiles>[R11]c1n[nH]c2cc[R1]cc12</smiles>

6<smiles>[R]c1n[nH]c2ccccc12</smiles>

10<smiles>COC(=O)Cn1nc([Al])c2c1C=C[R1]C(S)=C2</smiles><smiles>[R]c1nn(CC(=O)OC)c2ccccc12</smiles>

Scheme 1: Preparation of substituted methyl 2-(1H-indazol-1-yl)acetates. Reagents and conditions: (a) Et ${ }_{3} \mathrm{~N}, \mathrm{Boc}_{2} \mathrm{O}, \mathrm{DMAP}$, tetrahydrofuran; (b) $\mathrm{ArB}(\mathrm{OH})_{2}, \mathrm{Pd}\left(\mathrm{PPh}_{3}\right)_{4}$, aqueous $\mathrm{Na}_{2} \mathrm{CO}_{3}, 1,4$-dioxane, $120^{\circ} \mathrm{C}$; (c) methyl bromoacetate, $\mathrm{K}_{2} \mathrm{CO}_{3}$, acetone, $60{ }^{\circ} \mathrm{C}$; (d) alkylmagnesium bromide, $\mathrm{Et}_{2} \mathrm{O}, 0^{\circ} \mathrm{C}$; (e) Dess-Martin periodinane, $\mathrm{CH}_{2} \mathrm{Cl}_{2}$; (f) hydrazine hydrate, $175^{\circ} \mathrm{C}$. 
reaction was selected for the preparation of analogues bearing substituents around the central indazole core. This approach also permitted rapid replacement of the phenyl ring at C3 with functionalized phenyl rings and alternative heterocycles. Preliminary attempts to couple substituted 3-iodoindazoles 4 failed to produce isolable amounts of the desired product directly. Subsequently, the indazoles were protected as their tert-butyl carbamates 5 prior to undergoing palladium-mediated Suzuki reactions with various boronic acid partners. Under the reaction conditions, the carbamate-protecting group was also cleaved to afford the desired 3-arylindazoles, albeit as the unprotected systems 6. Alkylation with methyl bromoacetate and potassium carbonate in hot acetone completed the synthesis of compounds 7 .

In order to prepare 3-alkylindazoles, 2-fluorobenzaldehyde was first treated with alkylmagnesium bromides, and the resulting benzyl alcohols were immediately oxidized with Dess-Martin reagent. Alkyl phenyl ketones 9 and hydrazine hydrate were then reacted under microwave conditions to assemble the indazole ring 10. The ester side chain of $\mathbf{1 1}$ was installed under the same conditions described above for the alkylation of 3-arylindazoles.

\section{In vitro activity and SAR}

All of the compounds prepared above were evaluated for their ability to chemosensitize the $C$. albicans test strains $\mathrm{CaCi}-2$ and CaCi-8 towards fluconazole. As described above, the fungi were simultaneously incubated with test compounds and fluconazole $(8 \mu \mathrm{g} / \mathrm{mL})$ for 48 hours to determine if any combinations could fully inhibit fungal growth. The DMSO/fluconazole combination served as an internal control.

Substitution of the indazole core generally leads to a potency reduction to varying degrees (Table 1). The 5- and 6-positions can accommodate smaller functionalities such as methyl or chloro groups $(\mathbf{1 1}, \mathbf{1 5}$, and 17) and still retain modest efficacy. The inactivity of $\mathbf{1 4}$ compared to $\mathbf{1 7}$ suggests that the 6-position may occupy a slightly larger pocket. Electron-withdrawing substituents $(\mathbf{1 3}, \mathbf{1 8}$, and 19) appear detrimental to activity regardless of their position, while the weak potency of the methoxy compounds (12 and 16) suggests that there may be a limit to how far the western region may be extended. Pyridylindazole 20, wherein a nitrogen atom is inserted in the place of a carbon, displays no cellular activity. Based on these preliminary results, a more extensive SAR investigation of this region was postponed in order to explore other regions of the scaffold.

We proceeded to evaluate the SAR of the C3 substituent next (Table 2). Removal of the original benzene ring produces the

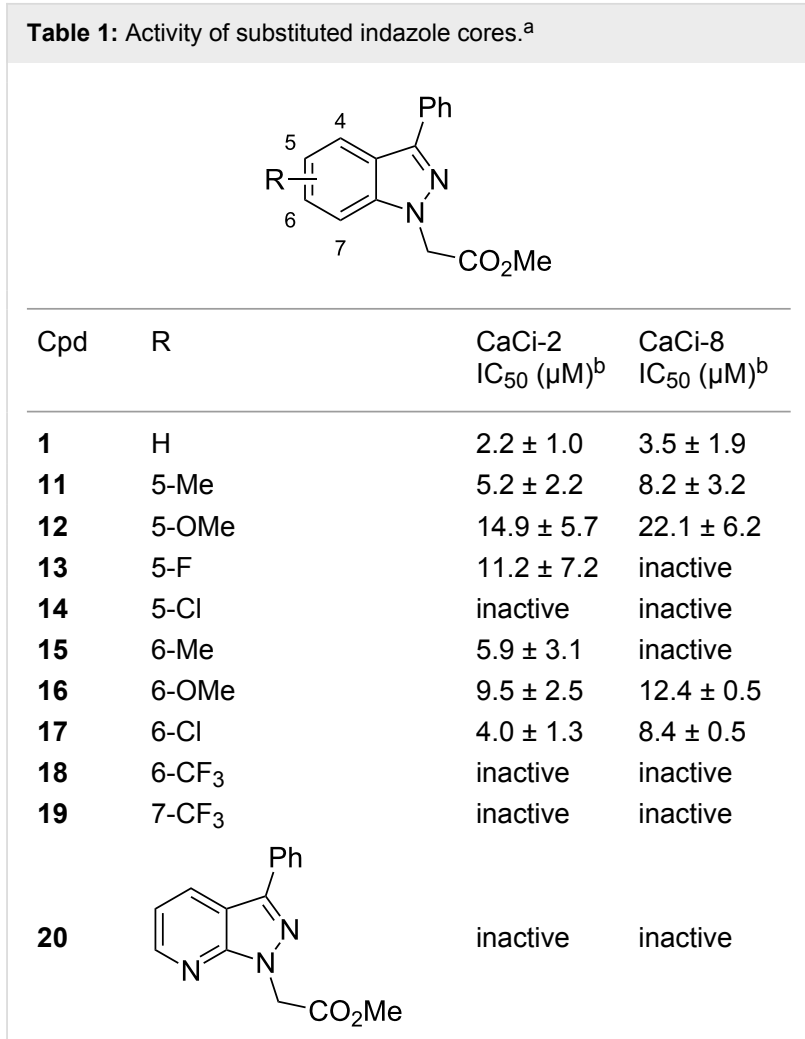

${ }^{\mathrm{a}} \mathrm{CaCi}-2$ and $\mathrm{CaCi}-8$ cells were incubated at $37^{\circ} \mathrm{C}$ for 48 hours with test compound and $8 \mu \mathrm{g} / \mathrm{mL}(26 \mu \mathrm{M})$ fluconazole. ${ }^{b}$ Average of at least three independent experiments, performed in duplicate. Inactive compounds displayed negligible activity at concentrations below $26 \mu \mathrm{M}$.

inactive analogue 21. Similarly, installing acyclic alkyl systems such as an ethyl (22) or tert-butyl group (23) does not yield active compounds. Proceeding to cycloalkanes, a SAR trend begins to emerge. With the smallest cycloalkane replacement, the cyclopropyl derivative $\mathbf{2 4}$ is inactive whereas the larger cyclohexane of $\mathbf{2 5}$ yields an active chemosensitizer $\left(\mathrm{IC}_{50}=2.3 \mu \mathrm{M}\right)$. When alternative heteroaromatic rings (26-29) were prepared, none of the examined systems possess any significant cellular activity.

One possible explanation for the observed activity is that the binding pocket includes a small cleft that is best occupied by flat structures. Compounds 21, 22, and $\mathbf{2 4}$ are presumably too small to fit properly into this crevice, while the tert-butyl derivative $\mathbf{2 3}$ may simply be too large. However, the inactivity of the heteroaromatic counterparts 26-29 may imply that more than a steric constraint is operative within this putative groove; a possible electronic requirement for this substituent may exist as well.

Returning to the original phenyl ring, various substituents were introduced at different positions about the ring to probe for further electronic and steric effects associated with this region 
Table 2: Investigation of 3-substituted indazoles. ${ }^{\text {a }}$<smiles>[R]c1nn(CC(C)=O)c2ccccc12</smiles>

\begin{tabular}{|c|c|c|c|}
\hline Cpd & $\mathrm{R}$ & 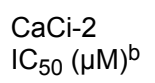 & $\begin{array}{l}\text { CaCi-8 } \\
I_{50}(\mu \mathrm{M})^{\mathrm{b}}\end{array}$ \\
\hline 21 & $-\mathrm{H}$ & inactive & inactive \\
\hline 22 & $-E t$ & inactive & inactive \\
\hline 23 & & inactive & inactive \\
\hline 24 & & inactive & inactive \\
\hline 25 & & $2.3 \pm 0.3$ & $6.0 \pm 1.7$ \\
\hline 26 & & inactive & inactive \\
\hline 27 & & inactive & $21.1 \pm 3.3$ \\
\hline 28 & & inactive & inactive \\
\hline 29 & & $12.9 \pm 1.7$ & inactive \\
\hline
\end{tabular}

${ }^{a} \mathrm{CaCi}-2$ and $\mathrm{CaCi}-8$ cells were incubated at $37^{\circ} \mathrm{C}$ for 48 hours with test compound and $8 \mu \mathrm{g} / \mathrm{mL}(26 \mu \mathrm{M})$ fluconazole. ${ }^{\mathrm{b}}$ Average of at least three independent experiments, performed in duplicate. Inactive compounds displayed negligible activity at concentrations below $26 \mu \mathrm{M}$.

(Table 3). With regards to steric requirements, it appears that neither the para- (compounds 30-34) nor ortho-positions (compounds 39 and 40) are particularly amenable to functionalization. While bioactivity is still observed with these substances, they all appear to be only weakly active $\left(\mathrm{IC}_{50}=2-8 \mu \mathrm{M}\right)$. Conversely, the meta-substituted systems $\mathbf{3 5}-\mathbf{3 8}$ prove to be the most conducive to potency. The methyl ether $\mathbf{3 6}$ is potent against $\mathrm{CaCi}-2\left(\mathrm{IC}_{50}=0.7 \mu \mathrm{M}\right)$ as is the $N, N$-dimethylamine variant $\left(37, \mathrm{IC}_{50}=0.8 \mu \mathrm{M}\right)$. The weakest compound of this series, 3-fluoro derivative $\mathbf{3 8}$, still shows low micromolar activity $\left(\mathrm{IC}_{50}=1.7 \mu \mathrm{M}\right)$. The weak activity of $\mathbf{3 8}$ may be tied to the electronegativity of fluorine. This is best illustrated with compounds 32-34. While the 4-fluoro analogue is a weak chemosensitizer of $\mathrm{CaCi}-2$ and $\mathrm{CaCi}-8$, introducing more electron-withdrawing substituents, such as trifluoromethyl (33) and cyano (34) groups, results in complete inactivity
Table 3: Substituent effects associated with the 3-phenyl ring. ${ }^{\text {a }}$<smiles>[R]c1ccccc1-c1nn(CC(C)=O)c2ccccc12</smiles>

\begin{tabular}{|c|c|c|c|}
\hline Cpd & $\mathrm{R}$ & $\begin{array}{l}\text { CaCi-2 } \\
I_{50}(\mu M)^{b}\end{array}$ & $\begin{array}{l}\text { CaCi-8 } \\
I_{50}(\mu M)^{b}\end{array}$ \\
\hline 1 & $\mathrm{H}$ & $2.2 \pm 1.0$ & $3.5 \pm 1.9$ \\
\hline 30 & $4^{\prime}-\mathrm{Me}$ & $4.8 \pm 2.5$ & $19.5 \pm 14.2$ \\
\hline 31 & 4'-OMe & $4.2 \pm 1.7$ & $14.1 \pm 6.4$ \\
\hline 32 & $4^{\prime}-\mathrm{F}$ & $8.3 \pm 2.8$ & $12.3 \pm 3.9$ \\
\hline 33 & $4^{\prime}-\mathrm{CF}_{3}$ & inactive & inactive \\
\hline 34 & $4^{\prime}-\mathrm{CN}$ & inactive & $20.5 \pm 0.3$ \\
\hline 35 & 3'-Me & $1.1 \pm 0.6$ & $1.9 \pm 0.9$ \\
\hline 36 & 3'-OMe & $0.7 \pm 0.3$ & $1.5 \pm 0.6$ \\
\hline 37 & 3'-NMe 2 & $0.8 \pm 0.1$ & $2.0 \pm 0.2$ \\
\hline 38 & $3 '-F$ & $1.7 \pm 0.4$ & $4.2 \pm 4.1$ \\
\hline 39 & 2'-Me & $5.3 \pm 0.5$ & $7.8 \pm 2.6$ \\
\hline 40 & 2'-OMe & $9.3 \pm 3.6$ & $11.4 \pm 1.7$ \\
\hline 41 & 3',5'-di-OMe & inactive & inactive \\
\hline
\end{tabular}

${ }^{a} \mathrm{CaCi}-2$ and $\mathrm{CaCi}-8$ cells were incubated at $37^{\circ} \mathrm{C}$ for 48 hours with test compound and $8 \mu \mathrm{g} / \mathrm{mL}(26 \mu \mathrm{M})$ fluconazole. ${ }^{\mathrm{b}}$ Average of at least three independent experiments, performed in duplicate. Inactive compounds displayed negligible activity at concentrations below $26 \mu \mathrm{M}$.

$\left(\mathrm{IC}_{50}>26 \mu \mathrm{M}\right)$. The activity of $p$-tolyl $\mathbf{3 0}$ and $p$-anisoyl $\mathbf{3 1}$ indicates that the inefficacy of $\mathbf{3 3}$ and $\mathbf{3 4}$ cannot be solely attributed to steric considerations. The inactivity of the 3,5dimethoxyphenyl ring (41) suggests the indazole's C3 substituent may reside in an asymmetric pocket.

As the most potent chemosensitizer of both C. albicans $\mathrm{CaCi}-2$ and $\mathrm{CaCi}-8\left(\mathrm{IC}_{50}=0.7\right.$ and $1.5 \mu \mathrm{M}$, respectively) with good solubility (55 $\mu \mathrm{M}$ in $\mathrm{PBS})$, compound $\mathbf{3 6}$ was nominated as MLPCN probe ML212. Exposure to human or murine plasma revealed significant chemical instability $(<10 \%$ remaining after $5 \mathrm{~h}$ incubation), and this is attributed to the ester hydrolysis of the side chain. Follow-up studies investigating the SAR of the side chain and addressing this liability will be reported shortly. Additional profiling of ML212 determined that the probe is nontoxic to $C$. albicans in the absence of fluconazole $\left(\mathrm{IC}_{50}>26 \mu \mathrm{M}\right.$ after $48 \mathrm{~h}$ incubation), neither does it show any toxicity towards murine $3 \mathrm{~T} 3$ fibroblasts $\left(\mathrm{IC}_{50}>26 \mu \mathrm{M}\right)$. Hsp90-dependent and calcineurin-dependent signaling pathways have been previously implicated in maintaining fluconazole resistance in C. albicans [21], but ML212 does not inhibit these pathways in yeast-reporter assays $\left(\mathrm{IC}_{50}>26 \mu \mathrm{M}\right)$. Identification of ML212's molecular target is ongoing, as well as 
efforts to determine the efficacy of ML212 against diverse mechanisms of fluconazole resistance, including biofilm formation, drug-target mutations, and efflux-pump amplification.

\section{Conclusion}

High-throughput screening of 300,000 compounds from the NIH's MLSMR collection identified several substances that potentiate the effect of fluconazole in fluconazole-resistant Candida albicans clinical isolates. Among the numerous hits, 3-phenylindazole 1 was selected for chemical optimization, resulting in the identification of 3-(3-anisoyl)indazole $\mathbf{3 6}$ as new small-molecule probe (ML212) to facilitate investigation of the various mechanisms used by $C$. albicans to withstand fluconazole. Elucidation of ML212's mechanism of action may afford new targets to exploit in the continuing efforts to develop novel antimycotics and combat increasingly prevalent drug-resistance. Samples of ML212 are available free of charge, on request.

\section{Supporting Information}

Detailed experimental protocols for cellular assays and for the preparation of representative compounds $\mathbf{2 5}$ and $\mathbf{3 6}$ are provided. Proton NMR spectra for all prepared compounds are also available.

\section{Supporting Information File 1}

Detailed assay protocols and compound synthesis. [http://www.beilstein-journals.org/bjoc/content/ supplementary/1860-5397-9-171-S1.pdf]

\section{Supporting Information File 2}

NMR spectra of reported compounds.

[http://www.beilstein-journals.org/bjoc/content/ supplementary/1860-5397-9-171-S2.pdf]

\section{Acknowledgements}

This work was funded by the NIH's MLPCN program (1 U54 HG005032-1 awarded to S.L.S.). BV, LW, and SL are grateful for funding from the NIH (1 R03 MH086456-01). The authors are grateful to Dr. Spencer Redding (University of Texas Health Science Center San Antonio) for graciously providing samples of C. albicans $\mathrm{CaCi}-2$ and $\mathrm{CaCi}-8$.

\section{References}

1. Martínez, J. L. Future Med. Chem. 2012, 4, 347-359. doi:10.4155/fmc.12.2

2. Hawkey, P. M.; Jones, A. M. J. Antimicrob. Chemother. 2009, 64 (Suppl. 1), i3-i10. doi:10.1093/jac/dkp256

3. Gould, I. M. Int. J. Antimicrob. Agents 2008, 32 (Suppl. 1), S2-S9. doi:10.1016/j.jiantimicag.2008.06.016
4. Vandeputte, P.; Ferrari, S.; Coste, A. T. Int. J. Microbiol. 2012, No. 713687. doi:10.1155/2012/713687

5. Pfaller, M. A.; Diekema, D. J. Clin. Microbiol. Rev. 2007, 20, 133-163. doi:10.1128/CMR.00029-06

6. Sanglard, D.; Odds, F. C. Lancet Infect. Dis. 2002, 2, 73-85. doi:10.1016/S1473-3099(02)00181-0

7. Lavigne, J.-P.; Brunel, J.-M.; Chevalier, J.; Pagès, J.-M. J. Antimicrob. Chemother. 2010, 65, 799-801. doi:10.1093/jac/dkq031

8. Gallo, S.; Chevalier, J.; Mahamoud, A.; Eyraud, A.; Pagès, J.-M.; Barbe, J. Int. J. Antimicrob. Agents 2003, 22, 270-273. doi:10.1016/S0924-8579(03)00215-2

9. Kim, J.; Campbell, B.; Mahoney, N.; Chan, K.; Molyneux, R.; May, G. Biochem. Biophys. Res. Commun. 2008, 372, 266-271. doi:10.1016/j.bbrc.2008.05.030

10. Cernicka, J.; Kozovska, Z.; Hnatova, M.; Valachovic, M.; Hapala, I.; Riedl, Z.; Hajós, G.; Subik, J. Int. J. Antimicrob. Agents 2007, 29, 170-178. doi:10.1016/j.ijantimicag.2006.08.037

11. The complete results of the HTS assay can be viewed online free of charge on PubChem. http://pubchem.ncbi.nlm.nih.gov/assay/assay.cgi?aid=1979.

12. Redding, S.; Smith, J.; Farinacci, G.; Rinaldi, M.; Fothergill, A.; Rhine-Chalberg, J.; Pfaller, M. Clin. Infect. Dis. 1994, 18, 240-242. doi:10.1093/clinids/18.2.240

13. DiGirolamo, J. A.; Li, X.-C.; Jacob, M. R.; Clark, A. M.; Ferreira, D. J. Nat. Prod. 2009, 72, 1524-1528. doi:10.1021/np900177m

14. Gamarra, S.; Rocha, E. M. F.; Zhang, Y.-Q.; Park, S.; Rao, R.; Perlin, D. S. Antimicrob. Agents Chemother. 2010, 54, 1753-1761. doi:10.1128/AAC.01728-09

15. Guo, X.-L.; Leng, P.; Yang, Y.; Yu, L.-G.; Lou, H.-X. J. Appl. Microbiol. 2008, 104, 831-838. doi:10.1111/j.1365-2672.2007.03617.x

16. Mai, A.; Rotili, D.; Massa, S.; Brosch, G.; Simonetti, G.; Passariello, C.; Palamara, A. T. Bioorg. Med. Chem. Lett. 2007, 17, 1221-1225. doi:10.1016/j.bmcl.2006.12.028

17. Additional information about the MLSMR can be found online at http://mli.nih.gov/mli/secondary-menu/mlscn/ml-small-molecule-reposit oryl

18. The Present Communication details a portion of the work previously described in official Probe Report submitted to the NIH upon project completion. The official Probe Report has been made available online by the NIH, free of charge: Hartland, C. L.; Youngsaye, W.; Morgan, B.; Ting, A.; Nag, P.; Burhlage, S.; Johnston, S.; Bittker, J.; Vincent, B.; Whitesell, L.; Dandapani, S.; MacPherson, L.; Munoz, B.; Palmer, M.; Lindquist, S.; Schreiber, S. L. "Identification of small molecules that selectively inhibit fluconazole-resistant Candida albicans in the presence of fluconazole but not in its absence - Probe 2". In: Probe Reports from the NIH Molecular Libraries Program [Internet]. Bethesda (MD): National Center for Biotechnology Information (US); 2010-. Available from: http://www.ncbi.nlm.nih.gov/books/NBK98920/

19. Youngsaye, W.; Vincent, B.; Hartland, C. L.; Morgan, B. J.; Buhrlage, S. J.; Johnston, S.; Bittker, J. A.; MacPherson, L.; Dandapani, S.; Palmer, M.; Whitesell, L.; Lindquist, S.; Schreiber, S. L.; Munoz, B. Bioorg. Med. Chem. Lett. 2011, 21, 5502-5505. doi:10.1016/j.bmcl.2011.06.105

20. Youngsaye, W.; Dockendorff, C.; Vincent, B.; Hartland, C. L.; Bittker, J. A.; Dandapani, S.; Palmer, M.; Whitesell, L.; Lindquist, S.; Schreiber, S. L.; Munoz, B. Bioorg. Med. Chem. Lett. 2012, 22, 3362-3365. doi:10.1016/j.bmcl.2012.02.035

21. Cowen, L. E.; Lindquist, S. Science 2005, 309, 2185-2189. doi:10.1126/science. 1118370 


\section{License and Terms}

This is an Open Access article under the terms of the Creative Commons Attribution License

(http://creativecommons.org/licenses/by/2.0), which permits unrestricted use, distribution, and reproduction in any medium, provided the original work is properly cited.

The license is subject to the Beilstein Journal of Organic Chemistry terms and conditions:

(http://www.beilstein-journals.org/bjoc)

The definitive version of this article is the electronic one which can be found at:

doi:10.3762/bjoc.9.171 